\title{
Prevention of Antibiotic Resistance Micro Flora Spreading by Analysing Surgical Infections' Microbiological Profile
}

\author{
Yuriy Lysiuk ${ }^{1}$, Olena Pilipovich ${ }^{2 *}$, Nataliia Pilipovich ${ }^{1}$ and Natalya Zakharko ${ }^{1}$ \\ ${ }^{1}$ Department of General Surgery, Lviv Danylo Halytsky National Medical University, Ukraine \\ 69 Pekarska str., Lviv, 79010, Ukraine \\ ${ }^{2}$ Department of Pharmacy, University of Muhammadiyah Malang, Indonesia \\ Jl. Bendungan Sutami 188A, Kota Malang, Jawa Timur, 65145 \\ *Corresponding author: olena.pilipovich11@gmail.com
}

\begin{abstract}
Background: Antibiotic resistance can be found among the top five most problematic issues that the international medical community pays a special attention to. The strategy of combating antibiotic resistance includes the rationalization of the antibiotic therapy, based on the regional specificity of the microbiological spectrum of diseases. Objective: To investigate the microbiological profile of main groups of soft tissue surgical infections and acute surgical abdominal diseases in the Department of Surgery and develop further regional recommendations for the antimicrobial therapy. Method: Retrospective analysis (2012-2013 years) of operated patients' bacteriological cultures in the Surgical Department of Lviv Communal City Clinical Emergency Hospital (Ukraine). The microflora of 646 samples (primary and secondary) was analyzed. 416 primary samples (2015 year) were studied separately to identify the resistance of the main pathogens. The analysis was carried out with the usage of the WHONET 5 database (standardized microbiological laboratory software). Result: In total, 12 microorganisms were detected: Gram-negative (58,3\%) and Gram-positive $(41,7 \%)$ bacteria. All results were sorted into the main surgical nosological groups: superficial infections of the skin and subcutaneous tissue (66\%), necrotic infections of soft tissues and deep phlegmons (8,5\%), acute surgical abdominal diseases (25,5\%). S.aureus was the dominant pathogen in superficial infections of the skin and subcutaneous tissue (243 samples; 63,9\%) and in necrotic infections and deep phlegmons (26 samples; 53,1\%), and E.coli was in acute surgical abdominal diseases (49 samples; 33,3\%). Particular attention was paid to antibiotic resistance of the clinical isolates of the dominant pathogen: generally, 37.3\% strains of S.aureus were methicillin-resistant (MRSA), including multidrug-resistant strains. Conclusion: The data of the microbiological profile is the objective basis for the regional clinical antibiotic therapy recommendations in the Department of Surgery. Antimicrobial resistance research and surveillance may be effective to prevent the spread of antibiotic resistance microflora.
\end{abstract}

Keywords: Microbiological Profile; Clinical Isolates; Antibiotics Resistance; Antibiotics; Clinical Recommendations

\section{INTRODUCTION}

Currently, the decreasing of antibiotic therapy effect is related to occurring and spreading of resistant strains (Leung et all 2011; World Health Organization 2011; Centers for Disease Control and Prevention US Department of Health and Human Services 2013; Sixty-seventh World Health Assembly 2014; European Centre for Disease Prevention and Control 2014; Kaye \& Pogue 2015; Sixty-eighth World Health Assembly 2015; Sartelli et al. 2016; Exner et al. 2017). According to the WHO Regional Committee for Europe, antibiotic resistance is one of the top five most problematic issues that the international medical 
community pays a special attention to (World Health Organization 2011). The problem of drug resistant bacteria is one of the main topics for the World Health Organization and continues to remain relevant (Sixty-seventh World Health Assembly 2014; Sixty-eighth World Health Assembly 2015). There is a sufficient number of public health action plans that have been formulated by international and national medical associations (Mattner et al. 2012; Tacconelli et al. 2014; Sixty-seventh World Health Assembly 2014; European Centre for Disease Prevention and Control 2014; Sixty-eighth World Health Assembly 2015; The White House 2015; Sartelli et al. 2016; Barlam et al. 2016; National Centre for Disease Control, Directorate General of Health Services, Ministry of Health \& Family Welfare, Government of India 2016). However, their effectiveness is not enough to successfully overcome the problem of the emergence and spreading of antibiotic resistant microflora.

The main conclusion of Antimicrobial Resistance Global Report on Surveillance by WHO, 2014: high resistance was noticed in all regions, for bacteria causing infections in both healthcare settings and in the community (World Health Organization 2014). The first and foremost goal in the prevention of Antimicrobial Resistance (AMR) should be their appropriate use (Centers for Disease Control and Prevention US Department of Health and Human Services 2013; World Health Organization 2015; National Centre for Disease Control, Directorate General of Health Services, Ministry of Health \& Family Welfare, Government of India 2016; Moolchandani et al. 2017). The key moment in this is a microbiological profile of a hospital and susceptibility pattern, which should be based on the accurate data (Zarb et al. 2012; World Health Organization 2015; Moolchandani et al. 2017). So collecting data is one of the most important tools. The Global Antimicrobial Resistance Surveillance System (GLASS) has been launched in May 2015 by WHO to support a standardized approach for AMR data collection, analysis and sharing at a global level (World Health Organization 2014; World Health Organization 2015). The local, national and global treatment strategies could be designed, based on the correct data (World Health Organization 2014). However, in some countries, there is no information obtained to this report (including Ukraine and Indonesia) (Zarb et al. 2012; World Health Organization 2014)

In the same time, obtained national data was usually based on proportions of resistant bacteria rather than proportions of resistant bacteria causing specific diseases or affecting defined populations (World Health Organization 2014). On the other hand, antimicrobial resistance surveillance guides the clinicians to choose appropriate empirical therapy. Such studies will be a key moment in establishing antimicrobial control and regulating the antimicrobial use (Zarb et al. 2012; Moolchandani et al. 2017)

\section{METHOD}

A retrospective analysis (2012-2013 years) of 646 bacteriological samples (primary and secondary) of operated patients in the Surgical Department of Lviv Communal City Clinical Emergency Hospital (Ukraine) was performed. The results of 576 consecutive microbiological samples were sorted into the main different clinical groups: surgical soft tissues infections and acute surgical abdominal diseases. In 2015 year the microflora of 416 primary samples was studied to identify the resistance of the main pathogens. Samples for bacteriological examination included pus from the site of surgical infections or wound exudates and peritoneal fluid that was collected from the site of diseases (intraperitoneal and retroperitoneal exudates). In the hospital-based microbiology laboratory samples were examined to detect bacteriological cultures. Identified aerobic bacterial strains were tested for antibiotic susceptibility by disk diffusion method based on national clinical and laboratory standards for antimicrobial susceptibility testing (Ukraine). The interpretation usually categorizes each result as susceptible, intermediate, and resistant. Methicillin-resistant 
Staphylococcus aureus was identified using oxacillin susceptibility test. In the samples with the association of pathogens, the sensitivity determination according to the dominant pathogen was performed. The analysis of microbiological tests was created by using WHONET 5 database (standardized microbiological laboratory software).

\section{RESULT AND DISCUSSION}

The bacterial microflora of 646 samples (primary and secondary) was analyzed. Anaerobic microorganisms weren't evaluated because need the special conditions for identification. Aerobic microorganisms were identified in $551(85,3 \%)$ samples; in 95 $(14,7 \%)$ the growth wasn't noticed. In $91.8 \%$ of samples the monoculture of microorganisms was identified, and in 8,2\% - associations. In total, 12 microorganisms were detected: Gramnegative $(58,3 \%)$ and Gram-positive $(41,7 \%)$ bacteria.

The spectrum of identified bacteria (551 isolates) is given in quantitative proportions (by detection frequency): Staphylococcus aureus $(\mathrm{n}=290 ; 52,6 \%)$, Esherichia coli $(\mathrm{n}=92$; $16,7 \%)$, Staphylococcus haemolyticus $(\mathrm{n}=51 ; 9,3 \%)$, Pseudomonas aeruginosa $(\mathrm{n}=34 ; 6,2 \%)$, Streptococcus $\beta$-haemolyticus $(\mathrm{n}=19 ; 3,4 \%)$, Proteus mirabilis $(\mathrm{n}=18 ; 3,3 \%)$, Klebsiella pneumoniae $(\mathrm{n}=12 ; 2,2 \%)$, Enterococcus faecalis $(\mathrm{n}=11 ; 2,0 \%)$, Acinetobacter baumannii $(\mathrm{n}=8 ; 1,5 \%)$, Enterobacter aerogenes $(\mathrm{n}=8 ; 1,5 \%)$, Citrobacter freundii $(\mathrm{n}=5 ; 0,9 \%)$, Streptococcus group D (non-enterococcal) $(\mathrm{n}=3 ; 0,5 \%)$. Generally, in the surgical department main pathogens $(76,8 \%)$ were S.aureus $(52,8 \%)$, E.coli $(16,7 \%)$ and Staph. haemolyticus $(9,3 \%)$.

According to the quantitative aspect, Gram-positive microflora was identified the most often $(n=374 ; 67,9 \%)$. The part of Gram-negative bacteria was $32,1 \%$ and the dominant group $(88,1 \%)$ of them were formed by 4 bacteria: E. coli, Ps. aeruginosa, Pr. mirabilis, Kl. pneumoniae. Generally, representatives of intestinal microflora were constant in $26,4 \%$ of cases. In addition, we found, that Enterobacteriaceae were noticed in $24,5 \%$ of isolates.

Results of consecutive microbiological samples $(n=576)$ were sorted into the main clinical groups: surgical soft tissues infections and acute surgical abdominal diseases. Additionally, the soft tissues infections were classified according to the anatomical principles into subgroups of superficial and deep infections. The superficial infections subgroup $(n=380 ; 66 \%)$ included the non-necrotizing infections of the skin and subcutaneous tissue (abscesses or superficial phlegmons). The deep soft tissues infections subgroup $(n=49 ; 8,5 \%)$ included necrotizing fasciitis, necrotizing cellulitis, and deep phlegmons. The clinical group of acute surgical abdominal diseases $(n=147 ; 25,5 \%)$ consists of complicated intraabdominal infections extends beyond the hollow organs of the gastrointestinal tract (including biliary and pancreatic infections) with either abscess formation or peritonitis.

The dominant pathogenVin superficial soft tissues infections subgroup were S.aureus $(63,9 \%)$, S. haemoliticus $(9,7 \%)$, E.coli $(7,6 \%)$. Main bacteria in the deep soft tissues infections subgroup were: S.aureus $(53,1 \%)$, S.haemoliticus $(10,2 \%)$. In the group of acute surgical abdominal diseases E.coli $(33,3 \%)$, Pseudomonas aeruginosa (10,9\%) and S.aureus $(6,8 \%)$ dominated. Antibiotic susceptibility of the main pathogens was proved. All $(100 \%)$ of S.aureus clinical isolates were susceptible to amikacin, gentamicin, vancomycin, and imipenem; E.coli - to amikacin, gentamicin, imipenem, ciprofloxacin; Staph. haemolyticus to gentamicin, vancomycin, and imipenem (100\%). The dominant group of Gram-negative bacteria (E. coli, Ps. aeruginosa, Pr. mirabilis, Kl. Pneumoniae) showed $100 \%$ sensitivity to gentamicin $(100 \%)$, imipenem $(97,5 \%)$, amikacin $(96,2 \%)$, cefotaxime $(77,4 \%)$.

Particular attention was paid to the antibiotic resistance of the dominant pathogens clinical isolates. The major part of S.aureus clinical isolates was resistant to imipenem (38\%), erythromycin (38\%) and even IV generation cephalosporins - cefepime $(37,3 \%)$ and 
cefpirome $(33,3 \%)$. In addition, attention was paid to the fact that $37,3 \%$ strains of $S$. aureus were methicillin-resistant (MRSA), including multidrug resistant. Clinical isolates of the dominant Gram-negative microflora were resistant to ampicillin $(87,1 \%)$, ciprofloxacin $(85,7 \%)$, cefepime $(33,7 \%)$, and ceftazidime $(29,7 \%)$.

At the first stage, the practical objective of our study was to establish the microbiological profile of major urgent surgical diseases in the Communal Emergency Hospital. The second stage was to identify the dominant pathogens and determine their sensitivity and resistance to antimicrobial drugs. The planned third stage will continuously monitor these data. A significant number of negative results of microbiological studies could be received because of an anaerobic microflora, which could not be identified as a result of the clinical laboratory insufficient capacity.

The results of our study allowed to identify key pathogens in various surgical groups in the surgical department. Main bacteria in the superficial and deep soft tissues infections was S.aureus (63.9\% and 53,1\% respectively) and in the acute surgical abdominal diseases E.coli $(33,3 \%)$. The obtained data allow to predict the kind of possible microbial agent and create a basis for the practitioner's empirical initial antibiotic therapy.

Admittedly, a serious problem in the treatment of surgical infection creates Gramnegative microflora and MRSA (Centers for Disease Control and Prevention US Department of Health and Human Services 2013; Tong et al. 2015; Kaye \& Pogue 2015; Sartelli et al. 2016; Exner et al. 2017). In 2008 coined the acronym of "ESKAPE" pathogens including Enterococcus faecium, Staphylococcus aureus, Klebsiella pneumoniae, Acinetobacter baumannii, Pseudomonas aeruginosa, and Enterobacter species to emphasize that these bacteria currently cause the majority of hospital infections and are the most important emerging threats associated with antibiotic resistance (Kaye \& Pogue 2015; Sartelli et al. 2016).

The increasing risk of antimicrobial resistance among gram-negative bacteria is a worldwide problem due to the potential for rapid spread of resistance mechanisms and limited treatment options (Centers for Disease Control and Prevention US Department of Health and Human Services 2013; Exner et al. 2017). In some regions, the problem of antibiotic resistance is especially relevant. In certain pathological conditions, isolates from Asia-Pacific countries showed the highest levels of antimicrobial resistance. Particularly, in complicated intra-abdominal infections a high prevalence of polymicrobial spectrum and antimicrobial resistance had been monitored (Kurup et al. 2014)

In the present study, the part of the Gram-negative bacteria in primary samples of emergency surgical diseases was $32,1 \%$. This group of pathogens is always problematic for treatment and could have a potential value as a source for further intra-hospital spreading (Kaye \& Pogue 2015; Sartelli et al. 2016; Exner et al. 2017). In addition, considering the short courses of antibiotic therapy for patients with local surgical infection, there is a risk of drug-resistant strains emergence and their further spreading in general population. Part of non-fermenting Gram-negative bacteria (Pseudomonas aeruginosa and Acinetobacter baumannii) wasn't high (7,6\%). However, taking into account their potential multi-drug resistance (MDR) (Centers for Disease Control and Prevention US Department of Health and Human Services 2013; Sartelli et al 2016; Moolchandani et al. 2017), the presence of this bacteria in the microbiological profile of emergency surgical diseases is important in the antibiotic therapy preferences.

Our results regarding the frequency of S.aureus $(52,6 \%)$ in surgical infection shows the same tendency as in other studies. At the same time, we paid attention to the fact that $37,3 \%$ strains of $S$. aureus were MRSA. This can be considered as an indirect indication of the high frequency of MRSA in the population of the region, as those microbiological studies were carried out in the beginning of the disease and exclude the probability of an intra-hospital 
source of pathogens (Kurup et al. 2014).The reason of MRSA spreading in the region population is the inappropriate use of antibacterial drugs in outpatient and inpatient settings (Kurup et al. 2014; The White House 2015; Sartelli et al. 2016; Exner et al. 2017). Moreover, for developing countries, important moments are immigration and tourism (Kurup et al. 2014; Exner et al. 2017).

Routine bacteriological culture and antibiotic susceptibility test are not helpful for clinicians. Identification of bacterial strains and susceptibility results take the same time, and results of antibiotic susceptibility are usually only available after $48 \mathrm{~h}$ and later (Sartelli et al. 2016; National Centre for Disease Control, Directorate General of Health Services, Ministry of Health \& Family Welfare, Government of India 2016). Hence, microbiological evaluations are not available for an immediate choice of initial antibiotic therapy. However, the results of investigation the microbiological profile of main urgent care diseases in hospital are helpful in guiding the choice of empiric therapy with adequate coverage proved spectrum of microflora. Moreover, the recommended initial antibiotic regimen should be adapted according to regional epidemiological data and resistance profile (endemic and epidemic situations) (Kurup et al. 2014; Tacconelli et al. 2014; Sartelli et al. 2016).

The problem of AMR is relevant at the international, national and regional levels as $\square \mathrm{HD}$ (Mattner et al. 2012; Centers for Disease Control and Prevention US Department of Health and Human Services. 2013; Kurup et al. 2014; The White House 2015; Barlam et al. 2016; National Centre for Disease Control, Directorate General of Health Services, Ministry of Health \& Family Welfare, Government of India 2016; Sartelli et al 2016; Exner et al. 2017; Moolchandani et all 2017). However, the report shows the gaps in antimicrobial resistance surveillance and they are the largest in a weak health care system (World Health Organization 2011).

Significant differences with regard to infection rates, the rates of microorganisms occurrence and antimicrobial resistance profiles have been identified between Asian and western countries, among different countries, among centers in the same country, and even among the hospital departments (Leung et al. 2012; Kurup et al. 2014; Kaye \& Pogue 2015; Exner et al. 2017). Generally, in the northern European countries, the AMR level is low, while the eastern countries have a higher level (Zarb et al. 2012; Tacconelli et al. 2014; Exner et al. 2017). According to the Ukrainian Ministry of Health 2013, there were 1,2 million bacteriological analyses done during the year. In 93,4 thousand of them - selected bacteriological culture. Multi-drug resistant strains were identified in 9,700 cases. There are many problems of monitoring antibiotic resistance in Ukraine, like lack of skilled staff, lack of technical equipment, lack of computers, slow implementation of modern laboratory technologies and lack of a national program to control the resistance to antibacterial drugs (Hlushkevych et al. 2013). Generally, the same situation can be observed in low- and middleincome countries (Sartelli, et al. 2016).

Mostly, data of resistant bacteria is usually based on proportions of resistant bacteria in the population, in the large regions or countries. Special attention is being paied to resistant bacteria in healthcare-associated and hospital-association infections (Leung et al. 2012; Mattner et al. 2012; Tacconelli et al. 2014; Tong et al. 2015; Moolchandani et al. 2017).

WHONET 5 is a standardized international control program for resistance, according to the WHO Global Strategy for Containment of Antimicrobial Resistance, 2001. This program is using in $~ 110$ countries (including Ukraine and Indonesia). WHONET 5 gives an opportunity to analyze the microbiological profile/spectrum of diseases and monitor antibiotic resistance.

In the newest studies, the main attention is paid to the proportions of resistant bacteria causing specific diseases or affecting defined populations (World Health Organization 2014). 
This approach is important in the clinical decision-making process and practicing in the field of emergency surgery. The choice of appropriate empiric antimicrobial therapy requires knowledge of the local resistance patterns among the most commonly isolated pathogens. A review of surveillance data and hospital-specific antibioticograms, including resistance patterns within the local institutions, can help in the selection of initial therapy (Kurup et al. 2014; Kaye \& Pogue 2015; Sartelli et al. 2016; Moolchandani et al. 2017). The rapid spread of antibiotic resistance indicates the need to implement an antibiotic stewardship program at the national and regional levels (Centers for Disease Control and Prevention US Department of Health and Human Services. 2013; Kurup et al. 2014; Tacconelli et al. 2014; The White House 2015; Kaye et al. 2016; Barlam et al. 2016; Sartelli et al. 2016; National Centre for Disease Control, Directorate General of Health Services, Ministry of Health \& Family Welfare, Government of India. 2016; Exner et al. 2017; Moolchandaniet al. 2017)

\section{CONCLUSION}

The data of the emergency diseases microbiological profile with detected susceptibility of main pathogens is the reliable basis for the antibiotic therapy protocol in the Department of Surgery. The appropriate initial antibiotic regimen should be determined according to the hospital antimicrobial resistance profile. Collecting data on antimicrobial resistance are very important tool for evaluation regional epidemiological situation. It will be helpful in establishing antimicrobial stewardship and regulate the antimicrobial use. Antimicrobial resistance research and surveillance may be effective for preventing the spread of antibiotic resistance microflora in its regional and global context.

\section{REFERENCES}

Barlam, T. F., Cosgrove, S. E., Abbo, L. M., Mac Dougall, C., Schuetz, A. N., Septimus, E. J., et al. (2016). Implementing an Antibiotic Stewardship Program: Guidelines by the Infectious Diseases Society of America and the Society for Healthcare Epidemiology of America. Clinical Infectious Diseases, 62(10), e51-77. https://doi.org/10.1093/cid/ciw118

Centers for Disease Control and Prevention US Department of Health and Human Services. (2013). Antibiotic resistance threats in the United States, 2013. Atlanta, GA: Centers for Disease Control and Prevention.

European Centre for Disease Prevention and Control. (2014). ECDC strategic multi-annual programme 2014-2020. Stockholm: European Centre for Disease Prevention and Control. http://ecdc.europa.eu/en/publications-data/ecdc-strategic-multi-annualprogramme-2014-2020

Exner, M., Bhattacharya, S., Christiansen, B., Gebel, J., Goroncy-Bermes, P., Hartemann, P., et al. (2017). Antibiotic resistance: What is so special about multidrug-resistant Gramnegative bacteria? GMS Hygiene and Infection Control, 12, 1-24. https://doi.org/10.3205/dgkh000290

Hlushkevych T.H. Stan monitorynhu antybiotykorezystentnosti v Ukrayini [Monitoring state of antibiotic resistance in Ukraine]. Tretya naukovo-praktychna konferentsiya, prysvyachena pam'yaty O.P.Viktorova "Bezpeka ta normatyvno-pravovyy suprovid likars'kykh zasobiv: vid rozrobky do medychnoho zastosuvannya" 23-24 zhovtnya $2013 \mathrm{~m}$. Kyev - The third scientific and practical conference devoted to the memory of O.P. Viktorov "Safety and regulatory support of medicines: from development to medical use" October 23-24, 2013, Kiev [in Ukrainian]. 
Kaye, K. S., \& Pogue, J. M. (2015). Infections Caused by Resistant Gram-Negative Bacteria: Epidemiology and Management. Pharmacotherapy, 35(10), 949-962. https://doi.org/10.1002/phar.1636

Kurup, A., Liau, K.-H., Ren, J., Lu, M.-C., Navarro, N. S., Farooka, M. W., et al. (2014). Antibiotic management of complicated intra-abdominal infections in adults: The Asian perspective. Annals of Medicine and Surgery, 3(3), 85-91. https://doi.org/10.1016/j.amsu.2014.06.005

Leung, E., Weil, D. E., Raviglione, M., \& Nakatani, H. (2011). The WHO policy package to combat antimicrobial resistance. Bulletin of the World Health Organization, 89, 390392. doi: 10.2471/BLT.11.088435

Leung, Y., Lai, R. W., Chan, A. C., Lo, J. Y., Ho, P., Wong, M. M., et al. (2012). Risk factors for community-associated methicillin-resistant Staphylococcus aureus infection in Hong Kong. Journal of Infection, 64(5), 494-499. https://doi.org/10.1016/j.jinf.2012.02.009

Mattner, F., Bange, F.-C., Meyer, E., Seifert, H., Wichelhaus, T. A., \& Chaberny, I. F. (2012). Preventing the Spread of Multidrug-Resistant Gram-Negative Pathogens. Deutsches $\quad$ Arzteblatt International, 109(3), 39-45. https://doi.org/10.3238/arztebl.2012.0039

Moolchandani, K., Sastry, A. S., Deepashree, R., Sistla, S., Harish, B. N., \& Mandal, J. (2017). Antimicrobial Resistance Surveillance among Intensive Care Units of a Tertiary Care Hospital in Southern India. Journal of Clinical and Diagnostic Research: JCDR, 11(2), DC01-DC07. https://doi.org/10.7860/JCDR/2017/23717.9247

National Centre for Disease Control, Directorate General of Health Services, Ministry of Health \& Family Welfare, Government of India. (2016). National Treatment Guidelines for Antimicrobial Use in Infectious Diseases. Version 1.0

Sartelli, M., Weber, D. G., Ruppé, E., Bassetti, M., Wright, B. J., Ansaloni, L., et al. (2016). Antimicrobials: a global alliance for optimizing their rational use in intra-abdominal infections (AGORA). World Journal of Emergency Surgery: WSES, 11, 33. https://doi.org/10.1186/s13017-016-0089-y

Sixty-seventh World Health Assembly. (2014). Combating antimicrobial resistance, $\begin{array}{lll}\text { including antibiotic resistance. } & \text { EB134.R13 }\end{array}$ http://www.who.int/iris/handle/10665/173018

Sixty-eighth World Health Assembly. (2015). Global action plan on AMR. WHA68.7 http://www.who.int/antimicrobial-resistance/global-action-plan/en/

Tacconelli, E., Cataldo, M.A., Dancer, S.J., De Angelis, G., Falcone, M., Frank, U., et al. (2014). ESCMID guidelines for the management of the infection control measures to reduce transmission of multidrug-resistant Gram-negative bacteria in hospitalized patients. Clin Microbiol Infect., 20 (Suppl. 1), 1-55. https://doi.org/10.1111/14690691.12427

The White House. (2015). National action plan for combating antibiotic-resistant bacteria. Washington, DC: The White House, March 2015.

Tong, S.Y.C., Davis, J.S., Eichenberger, E., Holland, T. L., \& Fowler, V.G. Jr. (2015). Staphylococcus aureus Infections: Epidemiology, Pathophysiology, Clinical Manifestations, and Management. Clinical Microbiology Reviews, 28(3), 603-661.

World Health Organization. (2014). Antimicrobial resistance: global report on surveillance. World Health Organization.

World Health Organization (2015). Global antimicrobial resistance surveillance system: Manual for early implementation. World Health Organization

World Health Organization. (2011). Report of the sixty-first session of the WHO Regional Committee for Europe. Baku: World Health Organization. 
Zarb, P., Coignard, B., Griskeviciene, J., Muller, A., Vankerckhoven, V., Weist, K., et al. (2012). The European Centre for Disease Prevention and Control (ECDC) pilot point prevalence survey of healthcare-associated infections and antimicrobial use. Eurosurveillance: bulletin europeen sur les maladies transmissibles = European communicable disease bulletin, November, $1-16$. https://www.researchgate.net/publication/233731059 